\title{
Mapeamento dos diálogos em fóruns de discussão online no Moodle por meio do inMapMoodle
}

\section{Dialogues mapping in online discussion forums in Moodle through inMapMoodle}

\author{
EDUARDO DE ALMEIDA RODRIGUES \\ Universidade Federal de Alfemas
}

\section{HENRIQUE DOS SANTOS WISNIEWSKI}

Universidade Federal de Alfemas

\section{GABRIEL GERBER HORNINK}

Universidade Federal de Alfemas

\begin{abstract}
Resumo: A crescente procura por cursos online gera uma demanda por instrumentos que auxiliem os formadores na compreensão das interações educacionais online. Focando no ambiente Moodle, desenvolveu-se a ferramenta inMapMoodle (c) que possibilita a geração de grafos direcionais (mapas de interação) dos fóruns de discussão. A partir da experimentação em dois cursos online de formação de tutores para cursos EAD, avaliou-se sua aplicabilidade em um contexto educacional, perpassando pela avaliação de sua usabilidade computacional. Esta, fundamentou-se nas heurísticas de Nielsen (checklist), além de incluir o Método de Inspeção Semiótica (MIS) e mapas de calor da tela. Aplicou-se questionário pós-curso focando na percepção de uso da ferramenta pelos participantes. Os dados evidenciaram a usabilidade e o potencial da ferramenta, indicando caminhos para seu uso e melhoria.
\end{abstract}

Palavras-chave: inMapMoodle. Fóruns de discussão. Usabilidade. Sociointeracionismo. Grafos.

\begin{abstract}
The growing demand for online courses generates a demand for tools that help trainers in understanding online educational interactions. Focusing on the Moodle environment, the inMapMoodle (c) tool was developed, which enables the generation of directional graphs (interaction maps) of discussion forums. From the experimentation in two online tutor training courses for EAD courses, its applicability was evaluated in an educational context, passing through the evaluation of its computational usability. This was based on the Nielsen (checklist) heuristics, in addition to including the Semiotic Inspection Method (MIS) and screen heat maps. A post-course questionnaire was applied focusing on the participants' perception of the use of the tool. The data showed the usability and potential of the tool, indicating ways for its use and improvement.
\end{abstract}

Keywords: inMapMoodle. Discussion forums. Usability. Sociointeractionism. Graphs. 
RODRIGUES, Eduardo de Almeida; WISNIEWSKI, Henrique dos Santos; HORNINK, Gabriel Gerber. Mapeamento dos Diálogos em Fóruns de Discussão Online no Moodle por Meio do inMapMoodle. Informática na Educação: teoria \& prática, Porto Alegre, v. 21, n. 3, p.38-61, set./dez. 2018

\section{Introdução}

O aumento crescente de cursos online permite conjecturar que essa modalidade seja um dos caminhos para o futuro da educação, o qual pode propiciar flexibilidade e relativa autonomia na aprendizagem. Nesse cenário, as TDIC ${ }^{1}$ vêm tornando fecundo o terreno para a interação entre indivíduos que procuram por formação em diversas áreas pois, em geral, rompem com o modelo clássico de emissão-recepção, de um sujeito para outro ou de um sujeito para todos (RODRIGUES; HORNINK, 2017).

A maioria dos cursos de educação a distância lançava mão de materiais didáticos especialmente desenhados para a auto-instrução, dissimulando o modelo tradicional de pedagogia. Tal modelo cedeu lugar ao que Resta e Laferrière (2007) nomeiam de aprendizagem colaborativa suportada por tecnologias, assegurando a autonomia do aprendiz por meio da interação e colaboração com seus pares.

Ambiente virtual de aprendizagem (AVA) é uma importante TDIC constituída por usuários e objetos de estudos projetando interação e comunicação por intermédio de uma plataforma (BEHAR; PASSERINO; BERNARDI, 2007). Dentre os mais utilizados está o Moodle, com destaque para a criação, hospedagem, oferta e gerenciamento de cursos a distância, além da adição de conteúdos (vídeos, jogos, documentos, hipertextos, etc) e a disponibilização de exercícios e atividades interativas.

Dentre as ferramentas de interação no Moodle, destacam-se os fóruns de discussão, que podem ser criados com diversas propostas e configurações de uso e não dependem de que o diálogo aconteça em tempo real. Tal assincronia, associada a um engajamento cognitivo, pressupõe uma discussão mais proveitosa com elaboração criteriosa das respostas ao tema proposto pelo formador e às contribuições dos colegas, além de flexibilizar a participação de um número maior de cursistas na discussão (RODRIGUES et al., 2016).

A distância física entre os sujeitos de um curso online coloca em dúvida a interação entre eles e, principalmente, a garantia de sua aprendizagem. A complexa organização dos fóruns dificultam o acompanhamento da quantidade e qualidade da interação bem como a análise detalhada das interações, da cronologia das mensagens e da integração entre tópicos e participantes com vistas à compreensão do diálogo (RODRIGUES; HORNINK, 2017). Tal acompanhamento, principalmente quando há muitas interações, passou a ser indispensável para uma moderação baseada no modelo proposto por Salmon (2004) que tende a assegurar a autonomia de aprendizagem online, ao contemplar cinco etapas: acesso e motivação, socialização, troca de informações, construção colaborativa do conhecimento e desenvolvimento pessoal. 
Assim, ambicionou-se, com o desenvolvimento do inMapMoodle, dar um passo em favor da moderação, visto que essa ferramenta gera representações visuais para monitoramento do processo de aprendizagem de maneira mais direta e contextualizada.

Um software educativo deve ser de fácil utilização de modo a não prejudicar as ações ou o conhecimento a ser passado para seu usuário, sob o risco de desmotivação de seu uso. Para tanto, realizaram-se avaliações de usabilidade que, conforme define a Norma International Organization for Standardization (ISO) 9241-11 (NBR 9241-11, 2002, p. 3), é a "medida na qual um produto pode ser usado por usuários específicos para alcançar objetivos específicos com eficácia, eficiência e satisfação em um contexto específico de uso".

Pretende-se, com este artigo, apresentar a avaliação de usabilidade e indícios da aplicabilidade do inMapMoodle possibilitando avaliar o potencial instrumento cultural para auxílio na moderação de cursos online.

\section{Moodle e seus fóruns}

Lançou-se o Moodle em 2002 como software livre, fruto do doutorado de Martin Dougiamas, objetivando ajudar educadores a criar e gerenciar cursos online (DOUGIAMAS e TAYLOR, 2009) e munido de ferramentas promotoras de interação para construção social do conhecimento e desenvolvimento colaborativo, sob uma perspectiva pedagógica do construtivismo social2. A versão atual estável é a 3.6, em pleno desenvolvimento por meio da comunidade mundial de desenvolvedores.

O AVA possui diversas ferramentas nativas e outras que podem ser instaladas por meio de extensões, categorizadas em temas, atividades e blocos, de acordo com a classe do conteúdo desenvolvido. O inMapMoodle ${ }^{3}$ é uma extensão da classe blocos, ou seja, após instalado, é necessário ativar a edição do curso para adicioná-lo como bloco à tela. Seu desenvolvimento foi estimulado pela capacidade do homem de interpretar com mais facilidade um conjunto de dados quando apresentados de forma visual. Miles e Huberman (1984) recomendam que a análise de dados contingenciados recebam suporte de representações visuais como gráficos e diagramas. Corroborando, Bosi $(1988$, p.) afirma que "a maioria absoluta das informações que o homem moderno recebe lhe vem por imagens. O homem de hoje é um ser predominantemente visual". Pode-se dizer que a visão de Bosi se intensificou nesses 30 anos, principalmente com o advento das tecnologias digitais e telas miniaturizadas.

Além disso, os relatórios do Moodle com relação ao fórum são mais quantitativos, relatando número de mensagens por participante ou cumprimento de metas (número de postagens e respostas) sendo a dinâmica da interação comunicativa entre os participantes e os indícios para compreensão do processo de ensino-aprendizagem desconhecidos.

Nesse contexto, o bloco foi concebido com o propósito de cartografar, a partir de grafos direcionais, as relações de forma visual, incrementando a esse conceito a possibilidade de uma

2 O construtivismo social pressupõe que o significado seja construído por meio de processos de interação social entre os sujeitos, ou seja, significados criados e compartilhados coletivamente (ZANELA SACCOL, 2009).

Número do registro de patente (INPI): 014120000886 (FERRAZ et al., 2012). 
"visualização quantitativa, relacional e direcional das interações entre os usuários em determinado fórum" (RODRIGUES et al., 2016).

\section{Materiais e métodos}

O desenvolvimento em si de um aplicativo não garante sua aplicabilidade, ou seja, que este cumprirá com os objetivos para o qual foi desenvolvido. Nesse sentido, fazem-se importantes as avaliações de usabilidade em contexto real de utilização, baseando-se nos princípios da avaliação de usabilidade computacional. Adotou-se uma abordagem quantitativa (FONSECA, 2002), recorrendo a uma "linguagem matemática para descrever as causas de um fenômeno". Sua natureza aplicada buscou compreender a usabilidade e a aplicabilidade da ferramenta que gera mapas de interação em fóruns e motivou-se pela necessidade de se produzir conhecimento para aplicação de seus resultados. Barros e Lehfeld (2000) apontam que a pesquisa aplicada tem por objetivo "contribuir para fins práticos, visando à solução mais ou menos imediata do problema encontrado na realidade". Em suma, pesquisas aplicadas buscam "resolver problemas ou necessidades concretas e imediatas" (APPOLINARIO, 2007).

A investigação se deu em duas etapas:

a) Avaliação da usabilidade do inMapMoodle, fundamentando-se nos cinco princípios de avaliação de usabilidade de softwares de Jacob Nielsen (1994), principalmente os relacionados a aspectos computacionais e comunicacionais, usando-se o Método de Inspeção Semiótica (MIS), o Checklist e o Mapa de calor;

b) Avaliação da aplicabilidade do inMapMoodle em dois cursos online sobre formação de tutores para moderação de cursos, sob a fundamentação sociocultural, nos quais se avaliou, a partir de questionários, a relação entre os mapas gerados e seu potencial de contribuição para a moderação dos fóruns, além de outras atividades.

\section{1 inMapMoodle: fundamentação do desenvolvimento e características}

AVAs fundamentam-se em teorias de aprendizagem que justificam seu desenvolvimento e orientam para o alcance de objetivos educacionais como é o caso da abordagem sócioconstrutivista na concepção do Moodle (MOODLE, 2019). Porém, a diversidade de recursos e atividades do Moodle amplia a possibilidade de utilização de outras abordagens pedagógicas que melhor se alinham com o potencial interativo de suas ferramentas como é o caso da teoria sócio-histórica que explora o potencial colaborativo dos fóruns com base nos estudos do pensador bielorrusso Lev Semyonovich Vygotsky (1896-1934), realçando o desenvolvimento do indivíduo como resultado de um processo sócio-histórico e atribuindo importância à linguagem e à aprendizagem nesse desenvolvimento. Seu cerne está na aquisição de conhecimentos partindo da interação do sujeito com o meio uma vez que a interação social tem papel fundamental no desenvolvimento das funções mentais superiores e internalização do conhecimento pelos indivíduos (VYGOTSKY, 1998). Essa teoria difere de outras abordagens essencialmente quanto à concepção de mediação, que permite a construção de novos conhecimentos, afetividades, relacionamentos, etc, reservando, ainda que não sejam 
contemporâneas às TDICs, o papel de instrumentos mediadores da comunicação entre os sujeitos (RODRIGUES et al., 2016).

Dessa maneira, o primeiro passo em direção a um fórum de discussão colaborativo foi dado no sentido de monitorar a interatividade por meio de indicadores que auxiliam o acompanhamento da discussão. A utilização de indicadores quantitativos e qualitativos aliados a representações visuais para auxiliar na moderação não é completamente nova. Um trabalho recente, por exemplo, utilizou-se de indicadores para criar fórmulas e gráficos para prever índices de participação e colaboração em um aplicativo chamado indeXMoodle, também concebido sob a abordagem sócio-histórica (FERRAZ; OLIVEIRA; HORNINK, 2015). Trabalhos recentes de Wong e Zhang (2018) também têm buscado, por meio de representações visuais, a compreensão de fóruns em cursos massivos abertos online (MOOCs), dotados de plataformas próprias e de grande volume e heterogeneidade de mensagens.

A expansão de cursos a distância em diversas instituições aliada à disponibilização de recursos do Programa Universidade aberta do Brasil (UAB) possibilitaram o desenvolvimento de materiais e tecnologias voltadas para o ensino e aprendizagem online. Somado a isso, a inspiração encontrada na ferramenta InterMap do TelEduc ${ }^{4}$ (UNICAMP) culminou no desenvolvimento do bloco inMapMoodle (Figura 1) na Universidade Federal de Alfenas (UNIFALMG), com a vantagem da quantificação das mensagens e do uso de setas direcionadas que representam graficamente as interações nos fóruns de discussão no Moodle (FERRAZ et al., 2016).

Figura 1 - Página inicial do inMapMoodle.

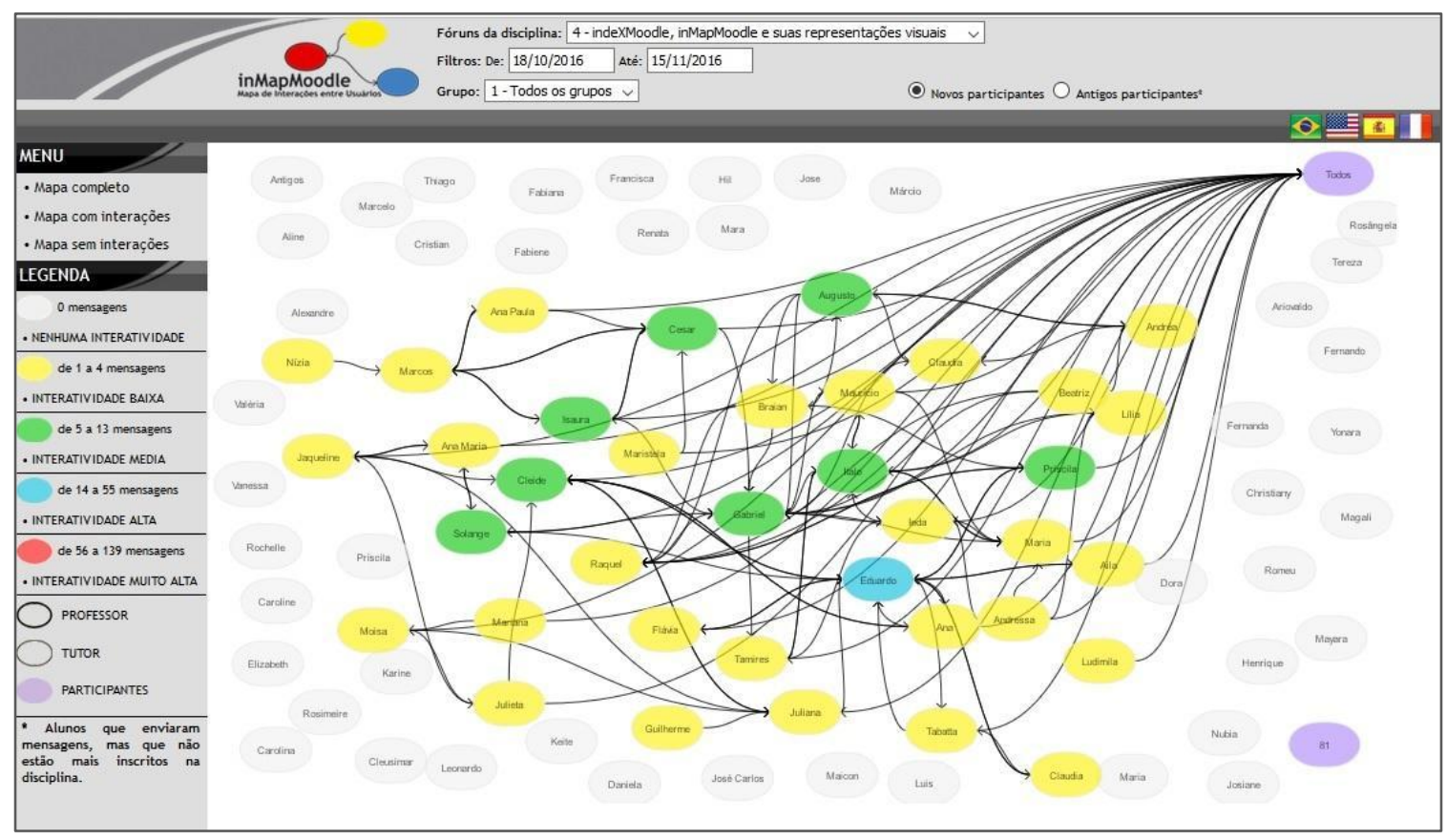

Fonte: FERRAZ et al, 2016. 
O desenvolvimento se fundamentou nos grafos direcionais, definidos como abstrações matemáticas que podem ser empregadas para representar uma rede complexa de dados (GABARDO, 2015). Entretanto, para a criação do sistema na linguagem $P H P^{5}$, os requisitos de software do Moodle também demandaram o uso das tecnologias (Quadro 1):

5 Sigla para Preprocessed Hypertext Pages ou "Páginas de Hipertexto Pré-processadas" - linguagem de programação por meio da qual o Moodle foi desenvolvido. 
Quadro 1 - Tecnologias utilizadas no inMapMoodle.

\begin{tabular}{|l|l|l|}
\hline \multicolumn{1}{|c|}{ Tecnologia } & \multicolumn{1}{|c|}{ Tipo } & \multicolumn{1}{c|}{ Vantagens } \\
\hline PHP & Linguagem interpretada & $\begin{array}{l}\text { Geração de conteúdo dinâmico na web; } \\
\text { Similaridade com o Moodle, Portabilidade, Velocidade e Simplicidade. }\end{array}$ \\
\hline JavaScript & $\begin{array}{l}\text { Bibliotecas: } \\
\text { a) Dracula Graph Library } \\
\text { b) jQuery }\end{array}$ & $\begin{array}{l}\text { a) Demonstração de grafos de maneira totalmente interativa; } \\
\text { b) Soluciona incompatibilidade entre navegadores, reduz o código e } \\
\text { permite a utilização de plug-ins de terceiros. }\end{array}$ \\
\hline
\end{tabular}

Fonte: Dos autores.

Além delas, estabeleceu-se conexão direta com o banco de dados de aplicação Moodle para execução de comandos SQL (Structured Query Language) para a aplicação de códigos das principais funcionalidades do inMapMoodle. Sua instalação se dá a partir do carregamento do pacote do bloco6 na área de administração do AVA e, quando disponibilizado pelo gestor e adicionado à página do curso, captura seu código de identidade (ID) no banco de dados e exibe os fóruns disponíveis.

A primeira versão, liberada em 2012, recebeu aprimoramentos demandados por uma avaliação de usabilidade que resultou na segunda versão de 2015, foco desta avaliação, destacando a instalação independente de banco de dados (RODRIGUES; HORNINK, 2017).

Quatro filtros dispostos no menu superior do inMapMoodle (Figura 2) podem ser ajustados para a geração dos mapas das interações:

a) Por fórum: A lista do tipo combobox é carregada permitindo a escolha de um fórum. Havendo uma ou mais mensagens, o fórum é colocado como ativo; do contrário, não ativo;

b) Por data: Filtra o intervalo de tempo em que as mensagens foram trocadas no fórum escolhido;

c) Por grupo: Importante para a divisão do trabalho dos formadores, o Moodle permite a distribuição dos cursistas em grupos e o carregamento destes no aplicativo possibilita a geração de mapas por grupo;

d) Por tipo de participantes: esse filtro permite que o mapa seja gerado a partir da situação do participante. Consideram-se novos participantes os que continuam inscritos no curso e antigos aqueles que deixaram o curso. Ressalta-se que as mensagens de participantes inativos são contabilizadas, entretanto, estas serão exibidas somente se o formador julgar necessário. Esse filtro é importante não só para o cálculo da escala, mas também para a geração correta do mapa. 
Figura 2 - Filtros no menu superior.

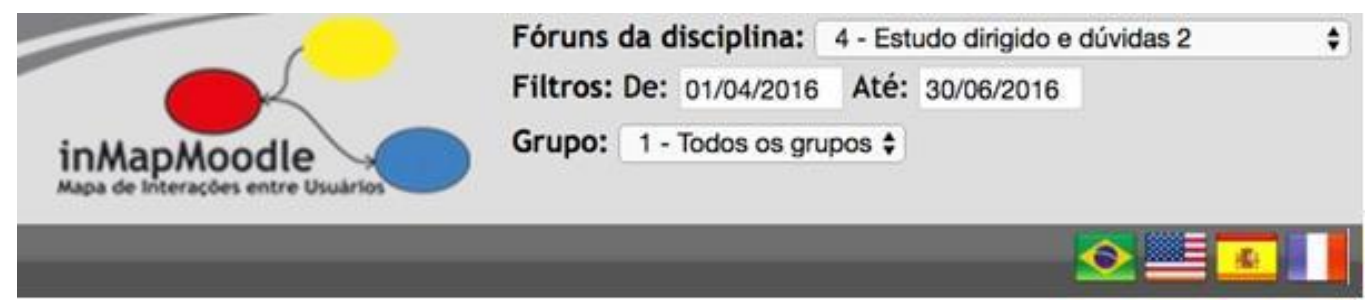

Fonte: FERRAZ et al, 2016

Destaca-se que o filtro por grupo surgiu na segunda versão, após testes de aplicabilidade em grandes turmas, com mapas de difícil compreensão gerados para todos.

O menu lateral (Figura 3) disponibiliza três opções de visualização do mapa definidas como:

a) Mapa completo: fornece um panorama de todos os participantes, uma vez que permite, no período escolhido, a visualização de todos, tanto os que interagiram quanto aqueles que não tiveram interações;

b) Mapa com interações: exibe somente os participantes com suas interações no período escolhido;

c) Mapa sem interações: exibe somente os participantes que não tiveram nenhuma interação no período escolhido.

Figura 3 - Menu lateral.

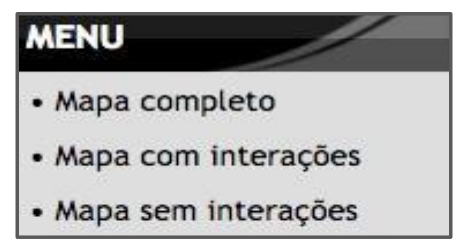

Fonte: FERRAZ et al, 2016.

É imprescindível para a interpretação dos mapas gerados que se consulte a legenda disponibilizada abaixo do menu lateral, à esquerda do mapa. O sistema representa cada participante do fórum por um balão colorido cuja interatividade é calculada a partir do número total de mensagens, atribuindo-se a este $100 \%$ de frequência e a partir do qual demonstramse as classes de interatividade: muito alta (vermelha para $41 \%$ a $100 \%$ ), alta (azul para $11 \%$ a $40 \%$ ), média (verde para $4 \%$ a $10 \%$ ), baixa (amarela para $1 \%$ a $3 \%$ ) e nenhuma interatividade (branca para 0\%) (Figura 4). Os balões têm contornos diferenciados para distinguir os perfis dos sujeitos, tendo como referência as principais categorias existentes em um curso online: professor (borda espessa), tutor (borda fina) e participantes ou cursistas (sem borda).

A Figura 4 representa a legenda sem cálculo $(A)$ e a legenda com cálculo gerado a partir de um total de 107 mensagens em um fórum (B). 
Figura 4 - Legenda do inMapMoodle.

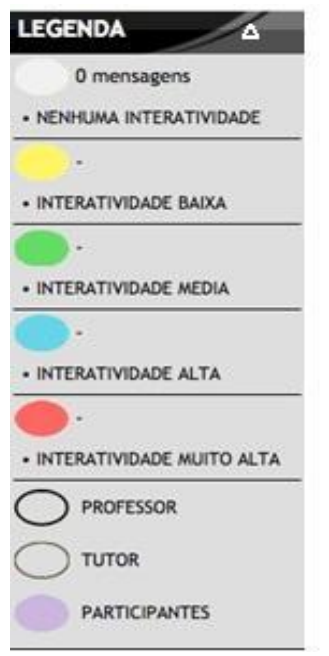

\begin{tabular}{l} 
LEGENDA \\
0 mensagens \\
- NENHUMA INTERATIVIDADE \\
\hline de 1 a 3 mensagens \\
- INTERATIVIDADE BAIXA \\
de 4 a 10 mensagens \\
- INTERATIVIDADE MEDLA \\
de 11 a 42 mensagens \\
- INTERATIVIDADE ALTA \\
de 43 a 107 mensagens \\
- INTERATIVIDADE MUITO ALTA \\
PROFESSOR \\
TUTOR \\
PARTICIPANTES
\end{tabular}

Fonte: FERRAZ et al, 2016

A troca de mensagens entre todos os participantes do fórum é apresentada no mapa com interações (Figura 5), indicando-se a direção (quem postou para quem), ou seja, o fluxo discursivo dos enunciados. $O$ balão Todos representa as mensagens que são enviadas para todos os usuários (postagem inicial no fórum) localizado no centro da representação (RODRIGUES et al., 2016). O total de participantes da discussão é exibido em um balão isolado que, assim como os demais balões, pode ser arrastado para melhor visualização. Ao passar o cursor sobre o balão, a função javascript hover permite visualizar nome e sobrenome do usuário.

Figura 5 - Mapa das interações de um fórum exemplo.

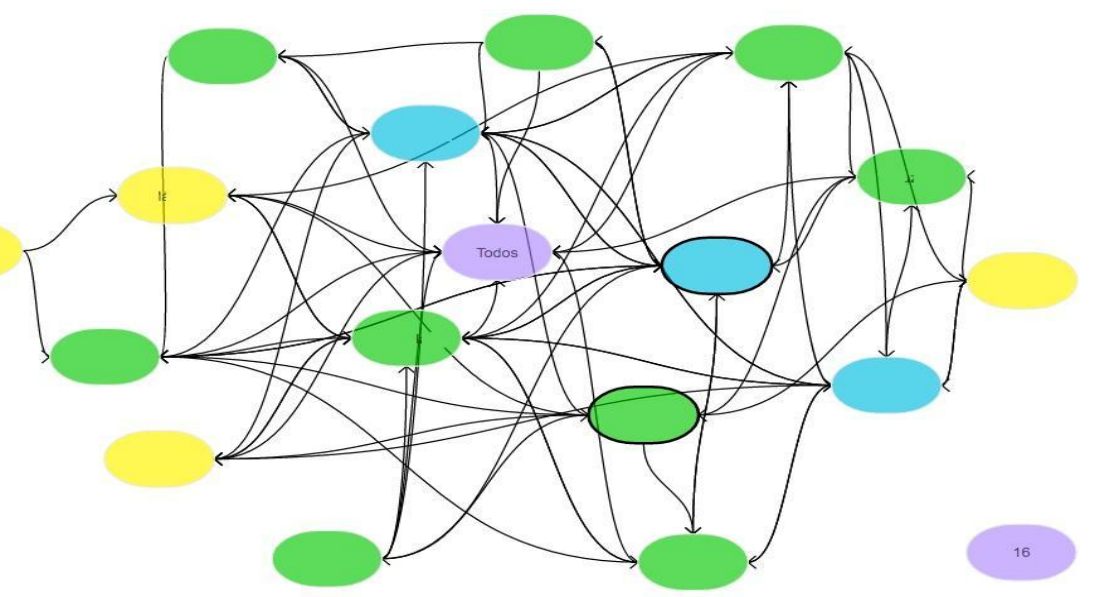

Fonte: FERRAZ et al, 2016.

O mapa completo (Figura 1) corresponde a uma fusão entre o mapa com interações e o mapa sem interações, tornando-se uma alternativa visual de uma possível métrica de avaliação de participantes de um fórum. 
Tanto o mapa com interações quanto o mapa completo destacam-se como indicadores mais úteis, tendo como principais aplicações:

a) Visualização panorâmica das relações;

b) Visualização da direção em que as interações ocorrem e do fluxo do enunciado;

c) Identificação dos sujeitos que monopolizam ou que estão à margem da discussão;

d) Identificação de sujeitos cuja emissão de mensagens destoa da recepção;

e) Identificação da atuação dos moderadores no fórum;

f) Dissolução de subgrupos de afinidades e promoção de uma interação mais homogênea.

\subsection{Avaliação de usabilidade}

A interface, segundo Baranauskas e Rocha (2000), é a comunicação entre homem e computador com a qual a usabilidade está intimamente relacionada, compondo o tripé da Interação Homem-Computador ou IHC (NIELSEN; LORANGER, 2007). Ao mesclar ciências exatas com ciências sociais, psicologia, biologia etc, a usabilidade é apontada como uma qualidade imanente ao produto que, mesmo funcional, será rejeitado se não tiver boa usabilidade.

Para Nielsen e Loranger (2007), a "usabilidade é um atributo de qualidade que avalia o quão fácil uma interface é de se utilizar" ou "a medida de qualidade da experiência de um usuário ao interagir com um produto ou um sistema". Em um contexto educacional, Reitz, Lima e Axt (2011) acrescentam que:

\footnotetext{
Ao utilizarem uma interface de pouca usabilidade por um longo período, os aprendizes podem incorrer em problemas como distúrbios de atenção e de acomodação dos novos conceitos, e dificuldades na retenção das informações quanto ao que está sendo aprendido (REITZ; LIMA; AXT, 2011, p. 137).
}

Em sua obra Usability Engineering (Engenharia de Usabilidade), Nielsen (1994) estabelece cinco parâmetros para mensurar a usabilidade de um produto:

a) Facilidade de aprendizado: o usuário consegue interagir rapidamente com o sistema, aprendendo a funcionalidade dos comandos e as opções de navegação;

b) Eficiência na utilização: tendo aprendido como funciona, o usuário consegue localizar a informação que necessita;

c) Facilidade na lembrança: o usuário dispensa a necessidade de reaprender como funciona;

d) Pequena exposição a erros: o usuário não comete muitos erros ou se os comete, são passíveis de recuperação;

e) Utilização agradável: o usuário sente-se satisfeito e gosta de interagir com o sistema.

Em 1995 Nielsen propõe um conjunto de dez qualidades desejáveis para qualquer interface, que chamou de heurísticas: visibilidade do status do sistema, mapeamento da compatibilidade sistema-mundo real, usuário com liberdade e controle, consistência e padrões, prevenção de erros, reconhecimento ao invés de lembrança, flexibilidade e eficiência de uso, desenho estético e minimalista, suporte para reconhecimento e recuperação de erros, além de ajuda e documentação. 
Nesse sentido, utilizaram-se os seguintes métodos:

a) Método de Inspeção Semiótica (MIS): análise da metacomunicação do projetista para com o usuário (signos estáticos, dinâmicos e metalinguísticos utilizados) transmitida por meio do sistema (DE SOUZA; LEITÃO, 2009). É realizado por um especialista em IHC e Engenharia Semiótica e objetiva identificar e sanar potenciais falhas de comunicação na interação usuário-sistema (DE SOUZA; LEITÃO, 2009);

b) Checklist: instrumento similar a um questionário com questões agrupadas de acordo com as heurísticas de Nielsen. A validação ocorreu com três usuários e a avaliação (após validação, com 12 usuários);

c) Mapas de calor: representações visuais dos padrões de exploração da interface por meio de cliques (gerado a partir do uso contínuo durante as avaliações do MIS, Checklist e durante os dois cursos).

O objetivo principal do MIS é a análise da metacomunicação do projetista, ou seja, identificar se os usuários percebem a interface da maneira como aquele gostaria. Nesse método, o avaliador incorpora o papel de usuário em busca de problemas com a interface (DE SOUZA; LEITÃO, 2009). Pode ser aplicado por um ou mais avaliadores e, neste trabalho, foi utilizado um avaliador (estudante de Ciência da Computação que trabalhou com a equipe de avaliação de usabilidade - não foi programador do sistema) seguindo o roteiro do Apêndice A.

Sua aplicação é composta das seguintes análises:

a) Signos metalinguísticos: compreendem as descrições, instruções ou explanações sobre a ação que fornecem. Busca e análise de documentação e ou ajuda, mensagens de erros, avisos, dicas, propagandas, etc.;

b) Signos estáticos: são imóveis e persistentes quando nenhuma interação está ocorrendo;

c) Signos dinâmicos: estão em movimento independente de ações dos usuários ou se transformam em resposta a uma interação. Identificação e avaliação do comportamento desses signos e da interação com os mesmos (DE SOUZA; LEITÃO, 2009);

d) Contraste e comparação das mensagens de metacomunicação: avaliação e comparação dos resultados das três etapas anteriores;

e) Avaliação da comunicabilidade do sistema: análise por parte do avaliador do comportamento de cada item da interface do sistema, para que o usuário realize determinada tarefa.

A avaliação heurística é bastante utilizada para encontrar problemas de usabilidade em uma interface e sua popularidade se deve à facilidade de entendimento do método, agilidade na sua aplicação (NIELSEN, 1995), além da ênfase no baixo custo (BIM; SALGADO; LEITÃO, 2016). O Checklist fundamentou-se nessas heurísticas (Quadro 2), com 13 perguntas a serem respondidas usando-se a escala de concordância de Likert (1989), variando de Discordo fortemente a Concordo fortemente, com escores de 1 a 5, uma vez que o padrão de respostas binárias (sim ou não) fornece poucos elementos para avaliação. Raramente há situações que a resposta é simplesmente binária, a grande parte das vezes acaba sendo uma escala de concordância e, ao usar o sistema binário, obtem-se erros de avaliação ou dados que não permitem uma avaliação minuciosa. 
Optaram-se pelas heurísticas que tinham relação com o projeto e uso do aplicativo. Por exemplo, não se incluiu prevenção de erros, uma vez que o aplicativo consiste em uma única tela, com poucas ações, que não geram erros ao usuário, assim, possibilitando-se ter um checklist mais sintético. As questões buscaram abranger os principais elementos do programa envolvidos na ação de gerar o mapa e que poderiam causar problema ou dificuldades ao usuário na geração e compreensão, sendo estas focadas nas heurísticas de Nielsen.

Quadro 2 - Quadro sintético dos critérios de avaliação do inMapMoodle por heurística.

\begin{tabular}{|c|c|c|}
\hline Questão. & Critério axaliado & Heurística correspondente \\
\hline Q.1 & $\begin{array}{l}\text { As opções dentro do painel do menu superior estão } \\
\text { ordenadas segundo algum critério lógico? }\end{array}$ & Reconhecimento ao invés de lembrança \\
\hline Q.2 & $\begin{array}{l}\text { As opções dentro do painel do menu lateral esquerdo estão } \\
\text { ordenadas segundo algum critério lógico? }\end{array}$ & Reconhecimento ao invés de lembrança \\
\hline Q.3 & $\begin{array}{l}\text { O sistema oferece valores padrões para acelerar a entrada } \\
\text { de dados no menu superior? }\end{array}$ & Consistência e Radrões. \\
\hline Q.4 & $\begin{array}{l}\text { Os itens interativos (clicáveis) se distinguem claramente } \\
\text { dos elementos estáticos (não clicáveis)? }\end{array}$ & $\begin{array}{l}\text { Consistência e Padrões / Desenho estético e } \\
\text { minimalista }\end{array}$ \\
\hline Q.5 & $\begin{array}{l}\text { A tela inicial apresenta excesso de informações que } \\
\text { confundem o usuário na geração do mapa? }\end{array}$ & $\begin{array}{l}\text { Desenho estético e minimalista / Visibilidade } \\
\text { do status do sistema }\end{array}$ \\
\hline Q.6 & $\begin{array}{l}\text { A ação gerada a partir da interação com os menus } \\
\text { corresponde ao esperado? }\end{array}$ & $\begin{array}{l}\text { Usuário com liberdade e controle / Prevenção } \\
\text { de erros }\end{array}$ \\
\hline Q.7 & $\begin{array}{l}\text { O vocabulário utilizado no sistema é familiar ao usuário, } \\
\text { evitando palavras difíceis? }\end{array}$ & $\begin{array}{l}\text { Mapeamento da compatibilidade sistema- } \\
\text { mundo real }\end{array}$ \\
\hline Q.8 & O sistema se adaptou à sua resolução de vídeo? & Flexibilidade e Eficiência de Uso \\
\hline Q.9 & $\begin{array}{l}\text { É possível a realização de uma tarefa em poucos passos ( } 1 \\
\text { a 5)? }\end{array}$ & Flexibilidade e Eficiência de Uso \\
\hline Q.10 & A opção de ajuda está bem localizada? & Ajuda e documentação / Prevenção de erros \\
\hline Q.11 & $\begin{array}{l}\text { As cores da legenda possibilitam a compreensão dos dados } \\
\text { gerados no mapa? }\end{array}$ & $\begin{array}{l}\text { Consistência e Padrões / Reconhecimento ao } \\
\text { invés de lembrança / Desenho estético e } \\
\text { minimalista }\end{array}$ \\
\hline Q.12 & $\begin{array}{l}\text { A diferenciação das bordas dos círculos na legenda } \\
\text { possibilita a compreensão da dinâmica da discussão por } \\
\text { perfil de envolvidos? }\end{array}$ & $\begin{array}{l}\text { Reconhecimento ao invés de lembrança / } \\
\text { Desenho estético e minimalista }\end{array}$ \\
\hline Q.13 & A seleção das datas é fácil? & $\begin{array}{l}\text { Usuário com liberdade e controle / Prevenção } \\
\text { de erros }\end{array}$ \\
\hline
\end{tabular}

Fonte: Dos autores.

O checklist obedeceu ao roteiro do Apêndice B, com 3 participantes para validação (estudantes de Ciência da Computação - Unifal-MG, que trabalham com avaliação de softwares, mas não faziam parte da equipe de desenvolvimento)

Para validação do checklist, aplicou-se o coeficiente Alfa de Cronbach ${ }^{7}$ para as respostas de três avaliadores iniciais, calculado a partir da soma das variâncias de cada questão, dividida pela variância do total de todas as questões e subtraindo-se o resultado de 1 . Multiplica-se o resultado pelo número de questões $(k)$, dividindo-o, em seguida, pelo número de questões menos $1(k-1)$, conforme a Figura 6.

7 Índice para estimar a confiabilidade de um questionário, desenvolvido pelo psicólogo estadunidense Lee Joseph Cronbach em 1951 (ALONSO; SANTACRUZ, 2015). 


$$
\alpha=\frac{k}{k-1}\left(\begin{array}{c}
\sum_{\mathrm{i}=1}^{k} S_{\mathrm{i}}^{2} \\
1-S_{\text {soma }}^{2}
\end{array}\right)
$$

Fonte: Dos autores.

Diferentes avaliadores encontram diferentes problemas e, portanto, é possível melhorar a eficácia da avaliação heurística quando se envolvem múltiplos avaliadores (NIELSEN, 1995). O autor relaciona o percentual de problemas que podem ser encontrados de acordo com o número de avaliadores (Figura 7).

Figura 7 - Proporção avaliadores / problemas encontrados.

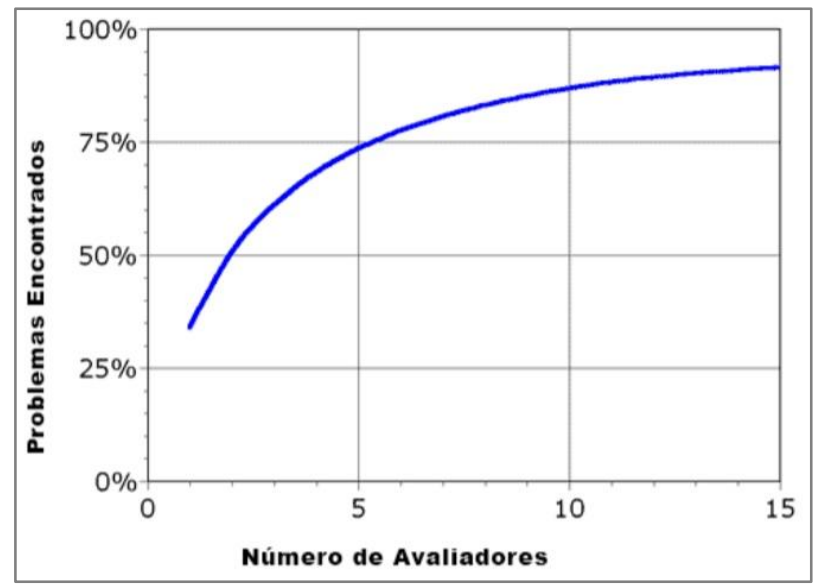

Fonte: Nielsen, 1995

Após validação, partindo do método de amostragem por conveniência, casual, enviou-se o convite para avaliação com roteiro (Apêndice B) para todos participantes do segundo curso online para formação de tutores, sendo a participação não obrigatória, de tal forma que obtiveram-se 12 avaliações. Destaca-se que, apesar da conveniência, o público do curso em questão é o mesmo que fora pensado para o aplicativo, desta forma, a escolha por esse grupo se justifica.

O mapa de calor (heatmap) é uma representação visual adequada para a análise aglomerada dos padrões de exploração visual de um grupo de usuários, de fácil uso e baixo custo (GRIGERA et al., 2017). Nela, as "áreas quentes" ou de maior intensidade sinalizam os locais onde a atenção foi mais fixada (BARRETO, 2012). Embora essa definição se refira mormente a mapas gerados a partir de interações visuais dos usuários com a interface (eyetracking), pode também ser adotada para as interações a partir de cliques na interface (clickmap), um dos objetos de análise neste trabalho. 
A versão atualizada do inMapMoodle foi utilizada por 78 pessoas e todas as interações com sua interface foram gravadas com o auxílio da ferramenta Hotjar8 (HOTJAR, 2019).

O Hotjar foi integrado à interface do inMapMoodle por meio de um código de rastreamento (tracking code). Um conjunto de instruções (script) na linguagem Java inserido no código fonte do sistema gera relatórios a partir dos cliques dos usuários, por meio dos quais pode-se identificar os locais que os usuários tiveram maior interação, verificando-se a coerência entre estes e os locais esperados de cliques, identificando possíveis erros de compreensão de itens interativos. Além disso, esses dados permitem um redesign dos componentes da tela, melhorando a localização de itens de maior uso.

\subsection{Avaliação de aplicabilidade}

Para este trabalho, considerou-se aplicabilidade como o cumprimento da função/objetivo para o qual o aplicativo foi desenvolvido, portanto, as questões se fundamentaram nos referenciais teóricos usados (teorias socioculturais) e no seu uso como potencial fornecedor de indícios das relações internas de diálogo do fórum que possibilitem o moderador atuar sobre este.

A aplicabilidade ${ }^{9}$ foi avaliada com base nos dados obtidos por meio de questionários aplicados ao final de dois cursos online oferecidos a tutores e candidatos a tutoria, público-alvo do inMapMoodle. Os cursos abordaram as principais ferramentas do Moodle, com ênfase na moderação de fóruns sob uma perspectiva sociointeracionista, além do inMapMoodle que fora utilizado como uma das ferramentas pelos cursistas na atividade de autoavaliação de participação e na atividade de moderação de fóruns de discussão, na qual eles deveriam atuar como moderadores em uma discussão no curso. Participaram do primeiro curso 73, com 34 respondentes e do segundo curso 107 com 45 respondentes ao questionário.

Construiu-se o questionário (Quadro 3) a partir do System Usability Scale (SUS) ou Escala de Usabilidade de Sistemas (BROOKE et al., 1996), incluindo assertivas específicas sobre a aplicação do sistema na moderação online. Adaptou-se a escala de concordância de Likert (1989) com escores de 1 a 5 para representar nuances entre Discordo fortemente e Concordo fortemente.

Parte das questões focou em identificar os referenciais teóricos (A.1), na importância dada aos fóruns (A.2) e na moderação destes (A.4), pois são base para compreensão e uso do inMapMoodle cuja construção se baseou nas teorias socioculturais. Esses dados contribuem para a compreensão das respostas às demais questões, pois a concepção de moderação pelo tutor/formador também passa pela ideia de que os conhecimentos são construídos pela interação entre seres humanos. Como as respostas às questões (Quadro 3) refletem a opinião do respondente sobre aspectos qualitativos e não sobre parâmetros técnicos, não se fez a validação do questionário como no Checklist.

\footnotetext{
8 https://www.hotjar.com/

9 http://www.aulete.com.br/aplicabilidade
} 
Quadro 3 - Questionário de aplicabilidade.

A.1 - Considero que as teorias sociointeracionistas podem fundamentar o modo como atuo em cursos a distância.

A.2 - Acredito que fóruns de discussão são ferramentas fundamentais para a construção do conhecimento.

A.3 - Tenho dificuldade em identificar o fluxo do discurso a partir das postagens dos cursistas nos fóruns no Moodle.

A.4 - O estímulo correto, por tutores, durante um debate virtual em fóruns no Moodle possibilita o aprofundamento da discussão.

A.5 - O número de mensagens de um cursista, em um fórum, é um indício de boa participação.

A.6 - A participação dos cursistas no fórum depende de sua predisposição em dialogar nessa ferramenta.

A.7 - Representações visuais das interações nos fóruns de discussão me ajudaria na forma de atuação nestes.

A.8 - Consigo ter uma visão global da situação do cursista a partir de suas participações simultâneas nas diversas ferramentas do Moodle.

A.9 - A ferramenta InMapMoodle@ fornece indícios úteis para a moderação dos fóruns.

Fonte: Dos autores.

Por se tratar de participantes de cursos online, disponibilizaram-se os questionários do checklist e de aplicabilidade por meio do aplicativo Google Formulários ${ }^{10}$ que permite a criação e disponibilização de questionários online para um grupo específico de pessoas que o acessam com usuário e senha, garantindo a confiabilidade das respostas.

\section{Resultados e discussão}

Durante a primeira etapa da avaliação da usabilidade (MIS), após uso da ferramenta simulando um contexto educacional (Apêndice A), analisaram-se os signos metalinguísticos, atentando-se para a ausência de mensagens de erro e falta de documentação de ajuda no inMapMoodle.

Dentre os signos estáticos, identificou-se baixa ergonomia do botão de seleção (novos participantes e antigos participantes) que deveria ser alterado ao clicar no texto e não na área marcada. A opção por participantes novos e antigos só é marcada quando se clica exatamente na área do círculo, tornando a usabilidade difícil para pessoas com deficiência ou com pouca habilidade com o mouse. Alguns botões podem confundir o usuário com elementos da interface, como é o caso do botão das bandeiras que representam os idiomas que não apresentam nenhuma interação com o passar do cursor.

Dentre os signos dinâmicos, a impossibilidade de seleção manual dos anos no calendário obriga o usuário a avançar ou retroceder as setas, mês a mês, até mudar o ano. Além disso, o sistema não se adapta bem a diferentes resoluções de telas.

Contrastando as avaliações das etapas anteriores, evidencia-se que a mensagem passada por Novos participantes e Antigos participantes (signos metalinguísticos) pode induzir o usuário a uma interpretação errônea e a uma ação não intencional, ensejando um ponto a ser ajustado com mais urgência. $O$ botão de Novos participantes pode ser interpretado como alunos que 
estão fazendo o curso, porém inclui aquele que continua no fórum mesmo sendo concluinte. 0 mesmo pode ocorrer com os Antigos participantes, pois um usuário pode imaginar que se trata da exibição apenas dos concluintes, mas serão exibidos tanto os antigos quanto os atuais. Uma sugestão para solucionar esse problema seria adicionar as opções de botão Incluir antigos participantes e Somente novos participantes.

Os filtros e seus efeitos (signos dinâmicos) podem ser de fácil entendimento para o usuário acostumado, mas poderiam ter mais clareza para usuários iniciantes. O número total de participantes aparece no canto inferior direito, podendo ficar oculto em alguns tamanhos de telas. O aprimoramento para facilitar a visualização desse número seria colocá-lo no canto superior esquerdo ou em forma de tópico na legenda, com destaque para a quantidade de participantes.

No padrão de cores da legenda (signos estáticos), o vermelho chama atenção para o volume de mensagens emitidas por um único participante, monopolizando uma discussão. Nessa mesma lógica, o amarelo representa a baixa interatividade, enquanto que interatividades intermediárias estão relacionadas com cores calmas (verde e azul), demandando menor preocupação.

Ademais, o registrou-se pelo MIS a ausência de um feedback ou animação de carregamento (ampulheta de loading), útil em conexões de baixa velocidade ou durante o processamento de muitas mensagens. Também não apresenta mensagem de erro ou de impossibilidade de retornar resultados para a tentativa de gerar um Mapa com interações com zero interação ou de travamento do sistema.

O checklist foi validado com a participação de três respondentes, suficientes para o cálculo do Alfa de Cronbach, cujo valor alfa acima de 0,8 $(a=0,82)$ garante uma consistência interna quase perfeita do questionário (LANDIS; $\mathrm{KOCH}, 1977$ ).

Após validação, obtiveram-se 12 avaliações, por respondentes que participaram da segunda oferta do curso, sendo que, de acordo com Nielsen (1995), esse número de avaliadores possibilita uma avaliação significativa, encontrando a maior parte dos problemas. Responderam 13 questões nomeadas de Q.1 a Q.13 que contemplaram o maior número de heurísticas de usabilidade plausíveis para o aplicativo, cujas respostas estão distribuídas no gráfico Box-plot de medianas e quartis (Figura 8). 
Figura 8 - Gráfico box-plot do Checklist.

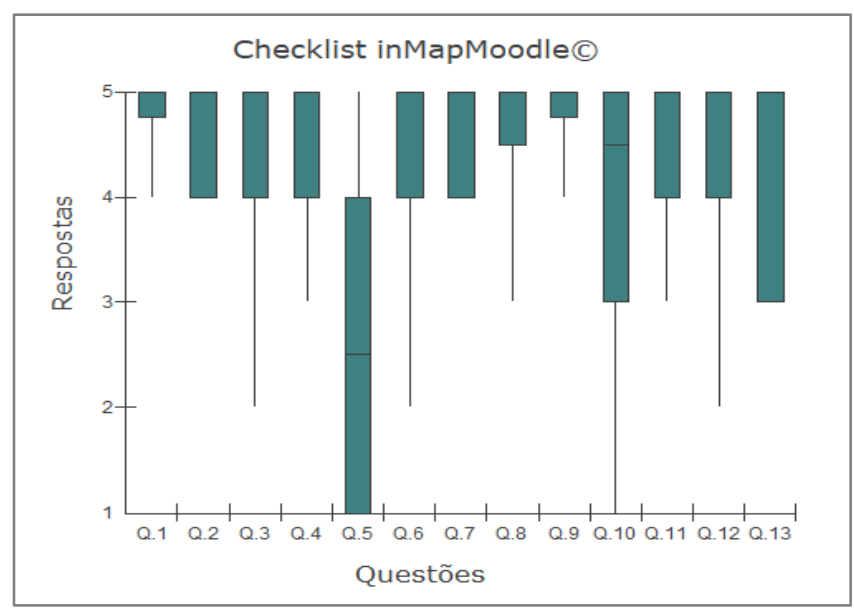

Fonte: Dos autores.

Consideraram lógica a organização do menu superior (Q.1) e do menu lateral (Q.2), 90\% dos respondentes, indicando que o sistema possibilita fácil reconhecimento da sequência de ações desses menus, sem ter que memorizá-las. Essa organização atende à heurística reconhecimento ao invés de lembrança que, segundo Cybis, Betiol e Faust (2010) "visa explorar as habilidades cognitivas humanas principalmente por meio de sistemas de menus e listas de seleção". Também concordaram fortemente, em resposta a Q.3, que valores padrão facilitam a entrada de dados no sistema, indicando a consistência de padrões.

Os itens clicáveis do inMapMoodle não se confundem com os estáticos (Q.4) para $75 \%$, indicando consistência de padrões e desenho estético e minimalista. Entretanto, essa heurística foi contrariada em Q.5, pois alguns acharam confusa a tela inicial que antecede a da geração do mapa, registrando uma média de 2,5 na escala. Isso também indica o não atendimento ao princípio da visibilidade do status do sistema que se refere à necessidade de o sistema fornecer um feedback adequado (CYBIS; BETIOL; FAUST, 2010).

As ações resultadas das interações com os menus (Q.6) são condizentes para $75 \%$, indicando liberdade e controle do usuário e prevenção de erros. O vocabulário utilizado no sistema também foi considerado compatível com a realidade para $75 \%$ dos usuários (Q.7), contemplando a heurística de compatibilidade do sistema com o mundo real (CYBIS; BETIOL; FAUST, 2010). A não adaptação da interface à resolução de tela (Q.8) não afetou $80 \%$ dos usuários enquanto $90 \%$ indicaram em Q.9 que é possível realizar uma tarefa em menos de 5 passos, atendendo ao princípio da flexibilidade e eficiência de uso. No entanto, em Q.10, 50\% consideraram que a opção ajuda está bem localizada, contrariando as heurísticas Ajuda e documentação e Prevenção de erros já que tal opção inexiste na interface. Talvez se refiram à pequena nota sobre Novos participantes e Antigos Participantes.

Reconhecer ao invés de lembrar e desenho estético e minimalista foram princípios novamente contemplados nas questões Q.11 e Q.12, pois 75\% consideraram que as cores da legenda facilitam a compreensão dos dados gerados no mapa, assim como as bordas com diferentes espessuras facilitam a compreensão da dinâmica da discussão por perfil. 
Em Q.13, 33,3\% assumiram neutralidade (escore 3) quanto à facilidade da seleção de datas, alertando para a melhoria do controle e liberdade do usuário e da prevenção de erros.

O mapa de calor foi a última etapa da avaliação da usabilidade, uma vez que precisava-se das ações dos usuários para geração deste. Destaca-se no mapa de calor (Figura 9), gerado a partir de 1831 cliques que a interface praticamente não deixou dúvidas quanto à localização dos itens clicáveis, sendo que a porcentagem de cliques fora dos botões ficou abaixo de 0,4\%, indicando clareza para os usuários.

Figura 9 - Mapa de calor (1831 cliques).

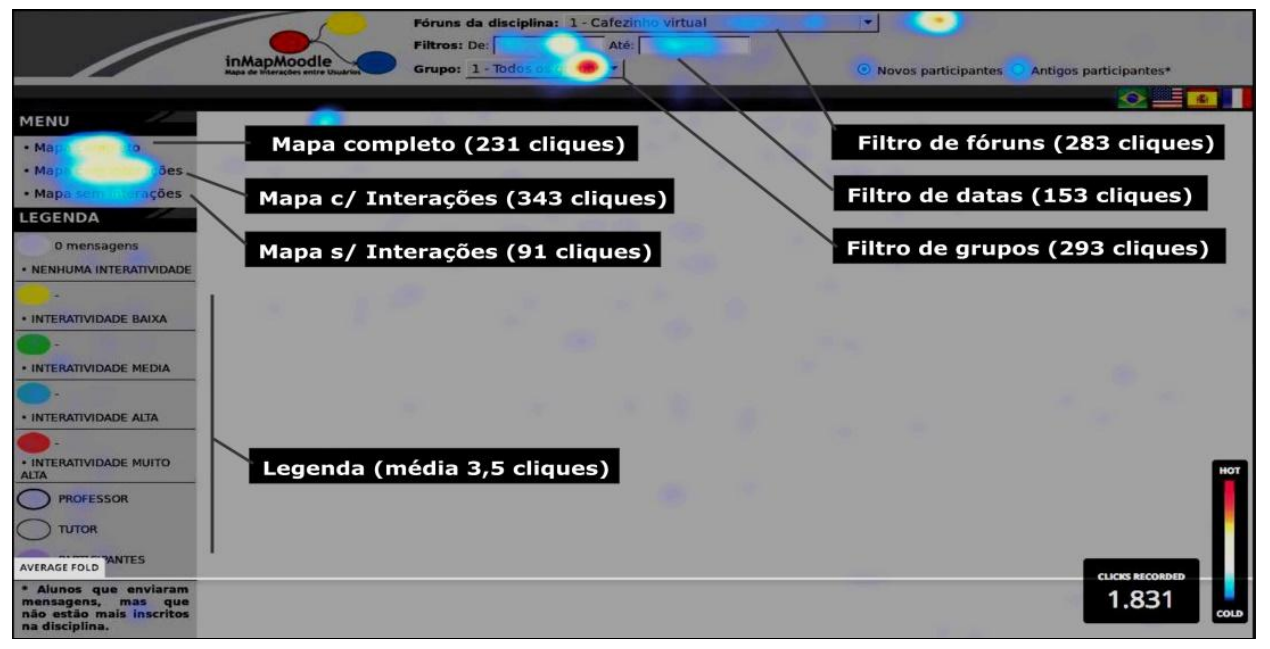

Fonte: Dos autores.

Ao clicar em uma determinada parte, significa que naquela interface existe um ponto de interesse para o usuário (KAUR; SINGH, 2015). O botão mais acionado foi o Mapa com interações (343 cliques), seguido do Mapa completo (231 cliques), sugerindo a possibilidade de inversão da posição desses botões.

Ressalta-se que se gerou o mapa de calor a partir das interações de todos os participantes, durante todo o segundo curso, do qual também fazem parte os 12 respondentes do checklist.

A avaliação da aplicabilidade ocorreu em duas etapas, pois teve como contexto dois cursos online de extensão oferecidos por uma universidade federal, primordialmente para tutores em atividade e futuros tutores.

Ao final do primeiro curso, 34 pessoas responderam ao questionário de avaliação da aplicabilidade (Quadro 3), correspondendo a 46,5\% dos 73 ingressantes, embora 31.5\% desses ingressantes tenham concluído todas as atividades do curso.

Para 75\%, a abordagem sociointeracionista pode fundamentar sua moderação em cursos online e para 80\%, os fóruns são fundamentais para a construção do conhecimento. Entretanto, tiveram média dificuldade (escore 3) na identificação do fluxo do discurso nos fóruns antes de utilizar o inMapMoodle. Concordaram que o estímulo dos tutores fomenta o aprofundamento da discussão sem condicioná-lo a um grande número de mensagens por cursista, pois isso depende de uma pré-disposição em dialogar. Para $75 \%$, as representações 
visuais das interações ajudariam na moderação e para $60 \%$, o perfil interativo do cursista pode ser conhecido a partir de suas participações nas diversas ferramentas do Moodle.

Ao final, 75\% concordaram fortemente que são úteis os indícios gerados por inMapMoodle para a moderação (Figura 10).

Figura 10 - Gráfico da Aplicabilidade no $1^{\circ}$ Curso.

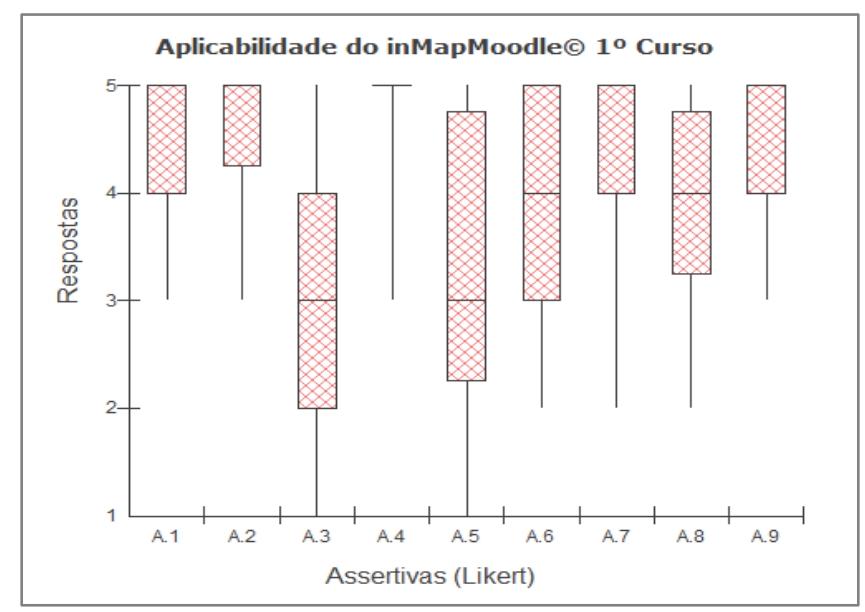

Fonte: Dos autores.

No final do segundo curso, 45 pessoas responderam, correspondendo a $42 \%$ dos ingressantes e também dos concluintes da totalidade do curso. Assinalaram altos escores (4 e 5) ao considerar que a abordagem sociointeracionista pode fundamentar sua atuação em cursos online, além da importância dos fóruns para a construção do conhecimento.

$\mathrm{Na}$ assertiva A.3, indicaram não ter dificuldades de compreender o fluxo do discurso nos fóruns, mesmo sem utilizar o inMapMoodle e concordaram que os fóruns podem estimular o aprofundamento da discussão. Houve neutralidade (escore 3) quanto à relação entre o número de mensagens de um cursista e o indício de boa participação, condicionando esse número à predisposição em dialogar. A partir da questão A.7 (Figura 11), ressalta-se que 90\% consideraram importantes as representações visuais das interações nos fóruns e concordou fortemente com a utilidade dos indícios gerados por inMapMoodle na moderação. 
Figura 11 - Gráfico da Aplicabilidade no 20 Curso.

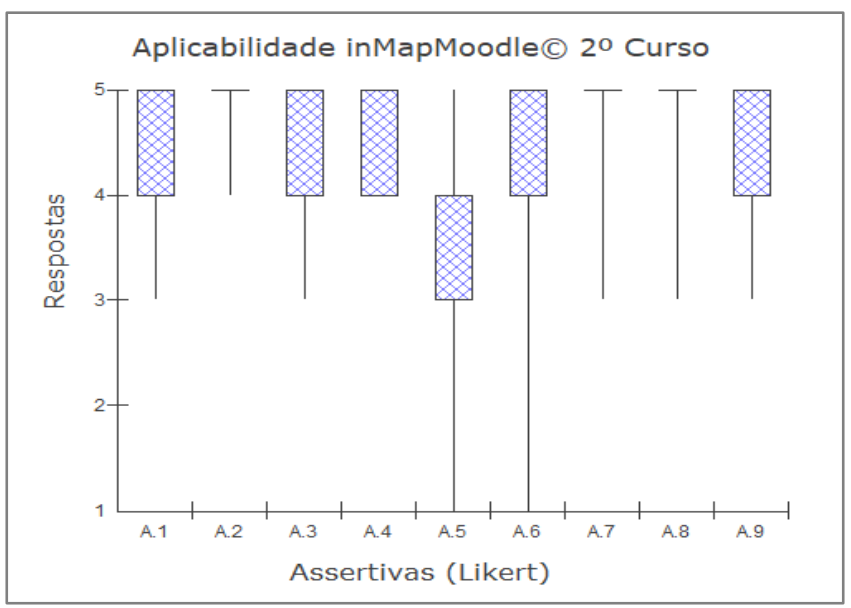

Fonte: Dos autores.

Embora nem todos tenham respondido, consideram-se suficientes os percentuais de respondentes, uma vez que correspondem a um número próximo ou superior ao número de concluintes, indicando boa representatividade. Merece destaque a coerência entre os resultados obtidos no MIS, checklist e mapas de calor indicando que, de um modo geral, inMapMoodle não possui problemas de usabilidade que interfiram em sua aplicabilidade.

Com predomínio de tutores entre os respondentes dos questionários, validou-se a aplicabilidade do inMapMoodle, uma vez que o consideraram de fácil uso e aprendizagem. Reconheceram o filtro por grupo, adicionado na segunda versão do sistema, como essencial e relacionaram facilmente as cores da legenda com as dos balões no mapa.

Ademais, identificaram no mapa os balões com pouco ou nenhuma linha de interação, que indicam sujeitos que estão à margem da discussão e que precisam de uma intervenção do moderador para sua inclusão no diálogo. Nesse mesmo raciocínio, consideraram o inMapMoodle como um ótimo recurso para auto-avaliação.

\section{Considerações finais}

O estudo apresentou aspectos da usabilidade do inMapMoodle, que indicaram seu potencial de uso e indícios de sua aplicabilidade, assim como elementos do aplicativo que ensejam correções e aprimoramentos, principalmente em pontos que podem levar o usuário à execução de ações indesejadas.

Identificou-se a partir do MIS incoerências em alguns signos da interface, por exemplo Novos e Antigos participantes, além do Total, que pode ser ocultado em algumas resoluções de tela. Em linhas gerais, embora se tenha notado a falta de um menu de ajuda e tela inicial pouco intuitiva para usuários iniciantes, inMapMoodle apresentou funcionamento adequado na exibição dos mapas.

Indicou-se, a partir do checklist, as potencialidades do sistema ao ponto de contemplar nove das dez heurísticas de Nielsen (1994), o que permite inferir que, embora algumas alterações no 
código sejam necessárias, tal aprimoramento visa garantir um resultado ainda melhor em relação à aplicabilidade.

O mapa de calor indicou que as áreas mais clicadas correspondem às regiões de filtros, menus e botões em geral, demonstrando que a ferramenta possui boa usabilidade, o que deixa de ser interferente na validação educacional.

Conforme demonstram os resultados, há uma coerência entre os métodos utilizados que apontam para a validação da aplicabilidade, visto que a maioria não encontrou problemas ao manipular a ferramenta considerando-a de fácil aprendizado e reconheceram o filtro por grupo como essencial. Ademais, além de identificarem facilmente balões com pouca ou nenhuma linha de interação, consideraram-no como ótimo recurso para auto-avaliação.

Dessa maneira, o inMapMoodle se posiciona como uma alternativa complementar à compilação tradicional de mensagens em fóruns de discussão, principalmente os de maior quantidade, revelando ao formador um panorama das interações e propiciando uma atuação mais incisiva em relação aos cursistas.

A versão mais atual desse bloco está disponível na aba de softwares para download 11 gratuito no sítio do Laboratório de Mídias Educacionais da UNIFAL-MG.

Espera-se que em suas futuras versões se possa desfrutar de indicadores referentes à nota atribuída a cada mensagem, de acordo com as escalas de avaliações das mensagens e levando em consideração sua relevância na construção colaborativa do conhecimento sob a perspectiva sócio-histórica de Vygotsky (1998).

\section{Reconhecimento}

À FAPEMIG, pela bolsa de Iniciação Científica.

\section{Referências}

ABNT - Associação Brasileira de Normas Técnicas, NBR 9241-11 - Requisitos Ergonômicos para Trabalho de Escritórios com Computadores - Parte 11, Orientações sobre usabilidade. 08/2002.

ALONSO, J. G.; SANTACRUZ, M. P. Cálculo e interpretación del Alfa de Cronbach para el caso de validación de la consistencia interna de un cuestionario, con dos posibles escalas tipo Likert. Revista Publicando, v. 2, n. 1, p. 62-67, 2015.

APPOLINÁRIO, F. Dicionário de metodologia científica: um guia para a produção do conhecimento científico. In: Dicionário de metodologia científica: um guia para a produção do conhecimento científico. 2007.

BARANAUSKAS, M. C. C.; ROCHA, H. V. Design e avaliação de interface homem-computador. São Paulo: UME-USP, p. 27, 2000.

BARRETO, A. M. Eye tracking como método de investigação aplicado às ciências da comunicação. Revista Comunicando, v. 1, n. 1, p. 168-186, 2012.

BARRoS, A. J. S.; LEHFELD, N. A. S. Fundamentos de Metodologia: Um Guia para a Iniciação Científica. 2 Ed. São Paulo: Makron Books, 2000.

11

https://www.unifal-mg.edu.br/Ime/softwares/ 
BEHAR, P. A.; PASSERINO, L. M.; BERNARDI, M. Modelos Pedagógicos para Educação a Distância: pressupostos teóricos para a construção de objetos de aprendizagem. RENOTE: revista novas tecnologias na educação. Porto Alegre, RS, 2007.

BIM, S. A.; SALGADO, L. C. C.; LEITÃO, C. F. Evaluation by Inspection: Comparing Methods of Practical, Cognitive and Semiotic Basis. In: Proceedings of the 15th Brazilian Symposium on Human Factors in Computer Systems. ACM, 2016. p. 9.

BOSI, A. Fenomenologia do olhar. O olhar. São Paulo: Companhia das Letras, p. 65-87, 1988.

BROOKE, J. et al. SUS-A quick and dirty usability scale. Usability evaluation in industry, v. 189, n. 194, p. 4-7, 1996. Disponível em: <http://hell.meiert.org/core/pdf/sus.pdf>. Acesso em: 01 mar. 2018.

CYBIS, W.; BETIOL, A. H.; FAUST, R. Ergonomia e usabilidade. São Paulo: Novatec, 2010.

DE SOUZA, C. S., LEITÃO, C. F. Semiotic Engineering Methods for Scientific Research in HCI. San Francisco: CA. Morgan \& Claypool, 2009.

DOUGIAMAS, M.; TAYLOR, P. Moodle: Usando Comunidades De Aprendizes Para Criar Um Sistema De fonte Aberta De Gerenciamento De Curso. In: Moodle: Estrategias Pedagogicas e Estudos de caso. Universidade do Estado da Bahia, 2009. p. 15-34.

FERRAZ, P. F. O. ; BUSQUEIRO, A., CAMPOS, R. S; SILVA, E. J; SILVA, R. B. ; BALBINO, R. R.; SOUZA, M. M.; HORNINK, G.G. InMapMoodle V.2, 2016.

FERRAZ, P. F. O. ; CAMPOS, R. S; SILVA, E. J; SILVA, R. B. ; BALBINO, R. R.; SOUZA, M. M.; HORNINK, G. G. InMapMoodle, 2012. Patente: Programa de Computador. Número do registro: 014120000886. Título: "inMapMoodle", Instituição de registro: INPI - Instituto Nacional de Propriedade Industrial.

FERRAZ, P. F. O.; DE OLIVEIRA, P. T.; HORNINK, G. G. Desenvolvimento e implementação de indicadores de colaboração e participação no Moodle. Informática na educação: teoria \& prática, Porto Alegre, v. 18, n. 1, 2015.

FONSECA, J. J. S. Metodologia da pesquisa científica. Fortaleza: UEC, 2002. Apostila. Disponível em: http:// www.ia.ufrrj.br/ppgea/conteudo/conteudo-2012-1/1SF/Sandra/apostilaMetodologia.pdf. Acesso em: 06 mar. 2018.

GABARDO, A. C. Análise de redes sociais: uma visão computacional. Novatec Editora, 2015.

GRIGERA, J.; GARRIDO, A.; RIVERO, J.M.; ROSSI, G. Automatic detection of usability smells in web applications. International Journal of Human-computer Studies, v. 97, 2017. Disponível em: <https:// doi.org/10.1016/j.ijhcs.2016.09.009>. Acesso em 07 de jan. 2019.

HOTJAR LTD. Hotjar: Heatmaps, visitor recordings, conversion funnels, form analytics, feedback polls and surveys in one plataform. 2019. Disponível em: <https://www.hotjar.com/>. Acesso em 06 jan. 2019.

KAUR, K.; SINGH, H. Analysis of Website using Click Analytics. International Journal of Science, Engineering and Computer Technology, v. 5, n. 6, p. 185, 2015.

LANDIS, J. R.; KOCH, G. G. The measurement of observer agreement for categorical data. biometrics, p. 159-174, 1977.

LIKERT, R. A technique for the measure of attitudes. Archives of Psychology, 140: 52, 1932. In: SAX, G. Principles of educational and psychological measurement and evaluation. Belmont, CA: Wadsworth Publishing Company, p. 491, 1989.

MILES, M. B., HUBERMAN, A. M. Data management and analysis methods. In: Coffey, A., Atkinson, P. Encontrar el sentido a los datos cualitativos: Estrategias complementares de investigación. Editorial Universidad de Antioquia. Medellín, 2005. 
MOODLE. Modular Object-Oriented Dynamic Learning Environment. 2006. Disponível em: <https:// docs.moodle.org/all/pt_br/Hist\%C3\%B3ria_do_Moodle>. Acesso em: 06 jan. 2019.

NIELSEN, Jakob. Usability engineering. Elsevier, 1994.

. How to conduct a heuristic evaluation. Nielsen Norman Group, v. 1, 1995.

NIELSEN, J.; LORANGER, H. Usabilidade na Web. Rio de Janeiro: Elsevier, 2007.

REITZ, D. S.; LIMA, J. V.; AXT, M. Usabilidade e Desempenho de Alunos em E-Learning. Informática na Educação: teoria \& prática, Porto Alegre, v. 14, n. 1, p. 137-151, jan./jun. 2011.

RESTA, P.; LAFERRIÈRE, T. Technology in support of collaborative learning. Educational Psychology Review, V. 19 , n. 1 , p. $65-83,2007$.

RODRIGUES, E. A.; BUSQUEIRO, A.; SILVA, R. B.; HORNINK, G. G. Fóruns de discussão no Moodle: proposta de apresentação visual das interações. In: SIED:EnPED - Simpósio Internacional de Educação a Distância e Encontro de Pesquisadores em Educação a Distância, 2016, São Carlos. Anais do SIED:EnPED Simpósio Internacional de Educação a Distância e Encontro de Pesquisadores em Educação a Distância. São Carlos: UFSCar, 2016. v. 1. p. 1-14.

RODRIGUES, E. A.; HORNINK, G. G. Sistemas de geração de indicadores de participação e colaboração no Moodle. In: XIV Encontro Virtual de Documentação em Software Livre (EVIDOSOL) e XI Congresso Internacional de Linguagem e Tecnologia online (CILTEC-online), 2017, Belo Horizonte. Anais do XIV Encontro Virtual de Documentação em Software Livre e XI Congresso Internacional de Linguagem e Tecnologia Online. Belo Horizonte: Texto Livre, 2017. v. 1. p. 1-6.

SALMON, G. Successful e-Learning through human mediators: training e-moderators. Nov@ Formação, v. 3, p. 22-24, 2004.

VYGOTSKY, L. S. A formação social da mente. 6. ed. São Paulo: Martins Fontes, 1998.

WONG, J.; ZHANG, X. MessageLens: A Visual Analytics System to Support Multifaceted Exploration of MOOC Forum Discussions. Visual Informatics, v. 2, n. 1, p. 37-49, 2018. Disponível em: Acesso em: 06 jan. 2019.

ZANELA SACCOL, A. Um retorno ao básico: compreendendo os paradigmas de pesquisa e sua aplicação na pesquisa em administração. Revista de Administração da Universidade Federal de Santa Maria, v. 2, n. 2, 2009. 


\section{Eduardo de Almeida Rodrigues}

Mestre em Educação pelo Programa de Pós-graduação em Educação (PPGE) da Universidade Federal de Alfenas (Mestrado Acadêmico). Possui pós-graduação em Design Instrucional para EAD pela Universidade Federal de Itajubá - UNIFEI (2012). Graduado em Ciências Biológicas pela Universidade Federal de Alfenas - UNIFAL-MG (2010). Membro do Grupo de pesquisa Inovações Tecnológicas no Ensino e da equipe do Laboratório de Mídias Educacionais, ambos da UNIFAL-MG. Tem experiência na área de Educação e Administração Educacional, ocupando o cargo de Técnico em Assuntos Educacionais na Pró-Reitoria de Graduação da UNIFAL-MG - Seção de Programas. Tem experiência em ilustração artística e softwares de ilustração digital. Tem experiência com tutoria a distância oriunda de sua atuação no curso de PósGraduação Lato Sensu Teorias e Práticas em Educação, oferecido pela UNIFAL-MG.

dadu.desenhista@gmail.com

\section{Henrique dos Santos Wisniewski}

Graduação em andamento em Ciência da Computação.

henriqueswisniewski@gmail.com

\section{Gabriel Gerber Hornink}

Possui bacharelado em Ciências Biológicas pela Universidade Estadual de Campinas (2003), licenciatura em Ciências Biológicas pela Unicamp (2006), especialização em gestão ambiental pela Unicamp (2006), mestrado em Biologia Funcional e Molecular (área Bioquímica, subárea Ensino) (2006) e doutorado em Ciências (2010), ambos pela Unicamp, na área de tecnologias educacionais. Tem experiência na área de Biologia Geral, com ênfase em formação de professores para o uso de Informática no ensino, atuando principalmente nos seguintes temas: software educacionais, educação a distância, formação de professores. Atua como co-editor da Revista de Ensino de Bioquímica (www.bioquimica.org.br) e revisor de diversas revistas da área de ensino. Atualmente está como professor de Bioquímica e de Tecnologias Educacionais na Universidade Federal de Alfenas (Unifal-MG) e desenvolve atividades no grupo de pesquisa Inovações Tecnológicas no Ensino (líder). Atua também como professor no programa de Pós-Graduação em Educação (Mestrado).

gabrielbio@gmail.com 


\title{
Apêndice A. Roteiro de avaliação de usabilidade pelo método de inspeção semiótica
}

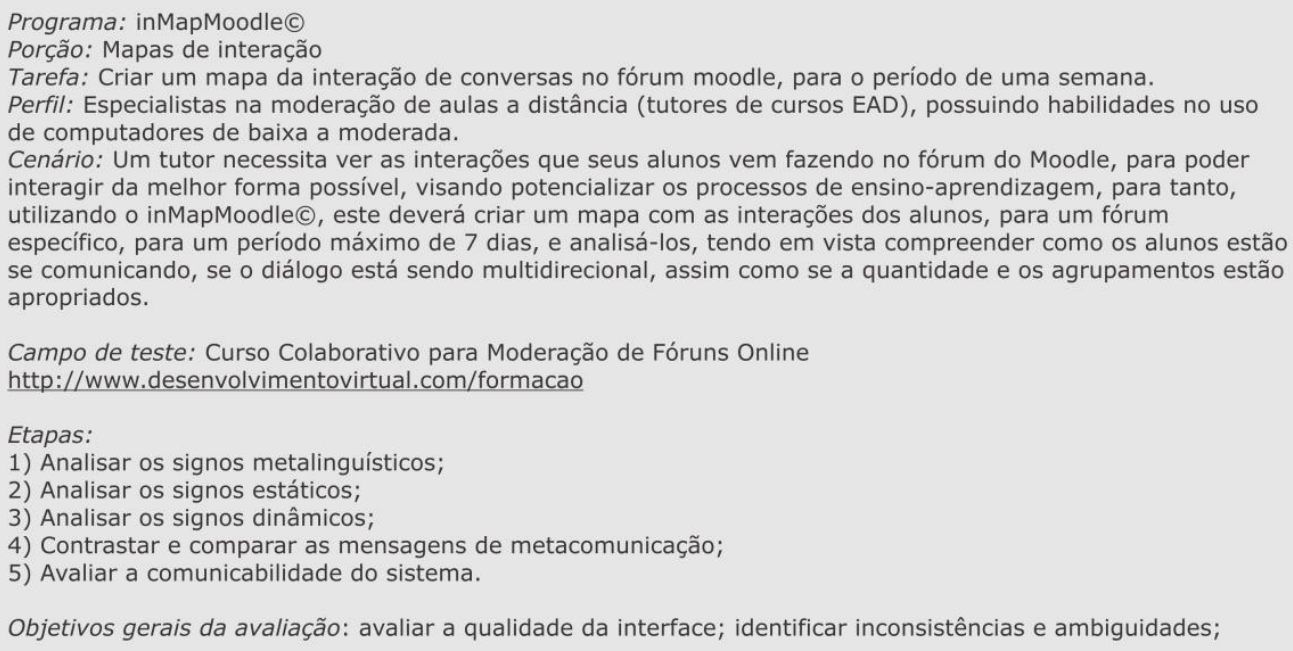

Objetivos gerais da avaliação: avaliar a qualidade da interface; identificar inconsistências e ambiguidades;

\section{Apêndice B. Roteiro de avaliação de usabilidade pelo método checklist}

\begin{abstract}
Este teste será de importante valia para a avaliação e validação da ferramenta inMapMoodle(c) no estado que se encontra, contribuindo para as melhorias futuras nesta.

O percurso que você fará possui duas partes, sendo estas com instruções muito parecidas.

1. Na primeira parte, você terá que gerar um mapa sem interações do fórum da disciplina Cafezinho Virtual, no curso Moderação de Fóruns Online, para analisar os dados da primeira semana do fórum, com todos os grupos. Após gerar o mapa, descubra quantos participantes não interagiram na semana.

2. Na segunda parte, você deverá gerar um mapa completo do fórum da disciplina Cafezinho Virtual, do mês inteiro, com a participação de todos os grupos e incluindo os participantes que deixaram a disciplina. Após gerar o mapa, olhe quantas mensagens no total foram enviadas.
\end{abstract}

